\title{
Imagen y memoria cultural: fotografía del libro antiguo
}

\author{
IDALIA GaRcía AgUiLAR \\ Centro Universitario de Investigaciones Bibliotecológicas \\ de la UNAM, 04510, México, D.F. Tel: 56230046 \\ E-Mail:pulga@cuib.unam.mx
}

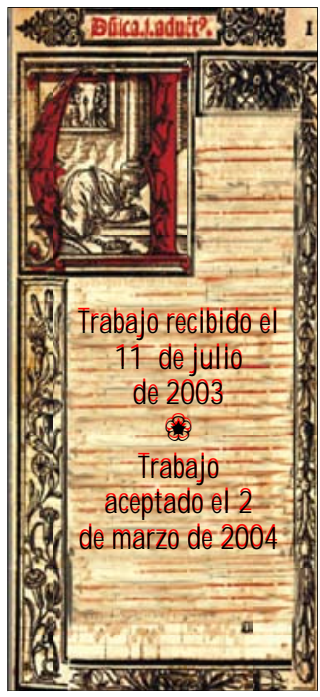

\section{RESUMEN}

Los libros antiguos son un objeto cultural entre cuyas características principales se encuentra la fragilidad material. Dicha fragilidad obliga a las instituciones custodias a determinar medidas de acceso restringido, al tiempo que se elaboran distintos productos culturales basados en fotografías de los materiales custodiados. La reproducción en México de materiales de bibliotecas y archivos implica diversas problemáticas sobre las que no se ha reflexionado mucho. Estas líneas analizan las características que estas reproducciones presenten y cómo se comprenden en términos legales, sociales y patrimoniales. El trabajo también propone soluciones para enfrentar la problemática que encaran las instituciones de custodia para reproducir originales con el objeto de socializar la herencia cultural heredada.

Palabras clave: Libros antiguos; Protección de documentos; Patrimonio Documental; Reproducción de originales.

\section{IMAGE AND CULTURAL MEMORY: PHOTOGRAPHY \\ OF RARE BOOKS \\ IDALIA GARCÍA-AGUILAR}

\section{ABSTRACT}

Rare books are cultural objects one of whose main characteristics is their physical fragility. This fact forces custodian institutions to restricted access to them, and at the same time elaborate different photographic cultural products. Reproduction of these materials in Mexican libraries and archives imply problems which have been given little thought. This paper analyses the characteristics of such reproductions and the way these are understood in legal, social and patrimonial terms. Also, with the aim of presenting our cultural inheritance to the public, solutions are also proposed to help custodian institutions face the difficulties of reproducing originals.

Keywords: Antiqe books; Documents Protection; Documental Heritage; Original Reproductions. 


\section{Las dras queconstitiyen d patrimmio nos hablany nosintepdan, son patri- monioparquenos hablan, nuestra memo na habla a través dedlas, aumqueno siempresabemos quénos dicen; para sa bedohabrá queesarhar en silenio, $\mathrm{e}$ sileniodela reflexión}

Joaquín Puig de la Bellacasa (2002) ${ }^{1}$

\section{INTRODUCCIÓN}

A ctualmente las constantes mutaciones del mundo de la información han cambiado radicalmente, como muchas otras cosas, las formas de trabajo de la investigación especializada. Como se sabe, en México la mayor parte de esta investigación se realiza en las universidades e instituciones públicas, sin que ello menosprecie el trabajo que también se desarrolla en las instituciones del ámbito privado. Esta investigación universitaria y pública debe responder en todos los aspectos que la sociedad se lo demande, en la medida en que es ésta la que financia con sus impuestos el trabajo universitario. También esta financiación pública nos otorga el privilegio de usar y aprovechar las ventajas que nos proporciona la tecnología moderna.

Las tecnologías de información ofrecen nuevas opciones de trabajo para la investigación que permiten, por un lado, agilizar los procesos de obtención y sistematización de información y, por el otro, también posibilitan mayor flexibilidad para transmitir a bajo costo los resultados de la investigación. Empero, esta realidad se contrasta con un mundo cada vez más dividido entre aquellos que pueden acceder a la tecnología y aquellos para quienes esta misma tecnología no forma parte de su realidad cotidiana.

El sentido más profundo de la investigación especializada, sobre todo de aquella que se realiza en las universidades públicas, es aportarle conocimiento al mundo social para que ese saber pueda modificar la realidad y producir mejoras para todos los seres humanos. Este enfoque parece notablemente más claro para las disciplinas “de ciencia pura" que para aquellas de orientación humanística. Sin embargo parecemos olvidar que ese mundo social es también afectado por factores económicos, políticos, sociales y culturales, que son el campo de trabajo, precisamente, delas humanidades.

1 De su texto "Visiones del patrimonio", en El patrimanioHistónicoArtísticoEspañd / coordinador Luis A. Ribot García. Madrid: Sociedad Estatal España Nuevo Milenio, 2002. p. 51. 
"El mundo no puede prescindir de los que lo interpretan", ${ }^{2}$ por esto la labor de la investigación universitaria resulta fundamental en momentos como éste, cuando el mundo atraviesa numerosas dificultades que han puesto en entredicho los valores humanos y culturales que deben sustentar nuestra acción cotidiana como miembros de una sociedad, presente y futura. Estos cambios mundiales han producido una importante preocupación internacional sobre el patrimonio cultural de la humanidad, pero el interés fundamental de garantizar la conservación de ese legado cultural no ha variado notablemente pese a las discusiones sobre el uso y el disfrute del patrimonio como derechos sociales, y a la implementación de las tecnologías de la información para mejorar el ejercicio de esos derechos.

Lo cierto es que la cuestión patrimonial ha sido atravesada sustancialmente por su relación directa con el derecho a la cultura y a la información como elementos fundamentales de la construcción y el mantenimiento de las sociedades democráticas. En efecto, el modelo democrático se posibilita en tanto más ciudadanos estén plenamente conscientes de sus derechos y obligaciones como miembros de una comunidad, sobre todo si esos mismos ciudadanos gozan de una vida cultural y social que les permita desarrollar su libertad y personalidad. Es aquí donde el patrimonio muestra su plena función social como un instrumento de transformación personal y comunitario que está en relación directa con el conocimiento del pasado y con la posibilidad de diseñarel presente.

Por ello la responsabilidad de la investigación universitaria es coadyuvar a que, mediante su ejercicio, los ciudadanos puedan conocer y disfrutar el legado cultural que legítimamente han heredado, y al mismo tiempo beneficiarse de los resultados de esa investigación. La tecnología y la investigación en el marco de valores humanos, sociales y culturales, puede mostrarle a todo ciudadano la riqueza cultural que lo distingue como miembro de una sociedad y al mismo tiempo recordarle su cercanía con el mundo. Este es el mayor reto que enfrenta toda persona que trabaja por conservar los bienes culturales: reconocerque sin función social, su trabajo no sirve absolutamente para nada.

\section{MEMORIA DOCUMENTAL Y DERECH OS CULTURALES: EL PROBLEMA DEL INTERÉ S PÚBLIC 0}

Con la Declaración Universal de los Derechos Humanos, el mundo depositó su confianza en la educación y la cultura para que los seres que habitan este planeta pudieran ser libres y responsables de su propia libertad. Una libertad que se ve en riesgo frente a las tecnologías de la información y el poder que ésta tiene para manipular los pensamientos y, portanto, las acciones delos hombres.

Desde esta perspectiva debemos reconocer que la tecnología de la información también ha afectado la forma de apreciar el patrimonio y, en este caso, de estudiarlo.

2 Jacques Marcovich. "Los desafíos de las universidades en Brasil y en el mundo", en LaUnivesidad enlasoiedaddd SigoXXI / Carlos Fuentes... [đ. al.]. Madrid: Fundación Santander Central Hispano: FCE, 2001. p. 41. 


\section{Investigacón Biblicteedógica v. 18 No. 36 enero/ junio de 2004}

Los mecanismos que la tecnología ofrece tanto para investigar el patrimonio como para recrear experiencias sociales sobre él mismo pueden ser inimaginables, pero su utilización requiere establecer mecanismos y formas que permitan que esa tecnología favorezca a todos los ciudadanos y no sólo a unos cuantos. La idea general es que toda información electrónica acerca del patrimonio puede ser accesible para todos, pero la pregunta es si todos tenemos el mismo acceso al mecanismo tecnológico por medio del cual podemos conocery utilizaresainformación.

En México esta premisa se fragmenta frente a las promesas de la tecnología y primordialmente frente a la necesidad de construir una sociedad democrática incluyente para todos. Según los datos del Banco Mundial, sólo 3.6 millones $^{3}$ de mexicanos pueden ser considerados internautas, es decir personas con acceso a las redes de información. Estos mismos datos indican que por cada mil personas existen 69 computadoras. Esta realidad social y económica determina en gran medida el acceso a la tecnología, y consecuentemente al universo de información que se mueve a través de ella.

Para nadie es un secreto el potencial que tienen las imágenes en un mundo como el nuestro. En el mundo del patrimonio se han construido íconos culturales mediante imágenes que no siempre benefician la comprensión social de los valores que han sido depositados en ese mismo patrimonio. Valores que justifican la mayor parte de las acciones de salvaguarda que se ejercen en numerosos países. No obstante, las imágenes se mueven ahora en un mundo digital del que no podemos aislarnos, en la medida en que ha determinado también nuevas formas de acceso social a los bienes patrimoniales.

Hoy en día se puede acceder desde distintos lugares a bienes culturales con la ayuda del espacio privilegiado de una máquina, aunque sin duda, nada puede reproducir la experiencia humana de recorrer y conocer ciertos espacios "mágicos" del patrimonio cultural y natural de la humanidad. En este sentido sirve como ejemplo de las posibilidades tecnológicas para el acceso social al patrimonio, el proyecto ArsVirtual ${ }^{4}$ delaFundación Telefónica de España que:

[...] tiene como objetivo la reproducción y difusión de los monumentos del patrimonio artístico español y latinoamericano en realidad virtual para Internet. Para ello, las recreaciones se realizan con tecnología de realidad virtual en tres dimensiones que reconstruye cada edificio en un entorno virtual con fidelidad y realismo, de forma que el visitante tiene la sensación de estar recorriendo físicamente ese monumento. ${ }^{5}$

3 Datos extraídos del Banco Mundial en http://devdata.worldbank.org/external/CPProfile.asp?SelectedCountry=MEX\&CCODE= MEX\&CNAME $=$ Mexico\&PTYPE $=\mathrm{CP}[$ Consultado: junio 2003].

4 La información se encuentra disponible en http://www.arsvirtual.org/ [Consultado: noviembre de 2003].

5 Fundación Telefónica. "El patrimonio histórico español y latinoamericano en recreaciones virtuales en Internet”, en Restauración \& Rehabilitacoón Reista Intemadinal da PatrimonioHistóica No. 80 (octubre de 2003). p. 62. 
Esta realidad y posibilidad es mucho mayor para aquellos bienes que por su naturaleza física de extrema fragilidad material requieren que se garantice su conservación mediante la creación de condiciones medioambientales especiales, que implican necesariamente restricciones para el acceso público. Entre estos bienes se encuentran prácticamente todos los objetos que conforman el patrimonio documental tal y como lo ha establecido el programa Memoria del Mundo de la UNESCO. ${ }^{6}$ Este mismo programa, desde su creación en 1992, estableció como uno de sus objetivos básicos el uso de la tecnología más adecuada para favorecer el acceso y disfrute social de la riqueza cultural que subyace en ese patrimonio.

Por su parte, el beneficio social de la tecnología también está reconocido en la Declaración de los Derechos Humanos Universales, por lo que ambos panoramas deberían constituir un marco idóneo de trabajo para la investigación especializada y los beneficios sociales que se esperan de ella. Pero para construir esta realidad debemos enfrentar antes otras dificultades prioritarias. Estas dificultades son primordialmente la creación de un orden jurídico que, desde el punto de vista patrimonial, regule todos los aspectos que se involucran en la vida cultural de los ciudadanos. Es decir, que se establezcan normas que involucren al creador, al objeto producido y a la institución de custodia a través de la cual se accede y disfruta de la cultura.

En México existe un desarrollo legislativo importante a ese respecto, pero no ha logrado conciliar todos los intereses involucrados y construir un universo integral que proteja la cultura y a la vez posibilite el beneficio social de ella. En este ámbito es precisamente donde se da encuentro el derecho de los autores y los derechos culturales y deinformación de los ciudadanos.

Es en ese espacio legal donde confluyen las personas y las instituciones. Lamentablemente son éstas últimas las menos beneficiadas con las acciones políticas y económicas del Estado mexicano, especialmente aquellas en las que se deposita la herencia cultural de los mexicanos: archivos, bibliotecas y museos. Ciertamente las leyes mexicanas en materia de cultura no colocan a estas instituciones en el lugar que parecería ser, precisamente, el másidóneo: la gestión de la riqueza patrimonial. El mundo de las instituciones, en el que habita el patrimonio cultural mexicano, conforma un complejo entramado de relaciones e intereses que no debe soslayarse y que responde a la forma de organización del propio Estado y de su devenir histórico.

En las complejas relaciones existentes en las instituciones de cultura que custodian bienes patrimoniales existe un aspecto que puede llegar a generar más de una controversia: los recursos financieros que requiere el patrimonio para su conservación y los que puedellegaragenerarsu aprovechamiento económico. Efectivamente:

6 Toda la información del programa disponible en http://www.unesco.org/webworld/mdm/en/index_mdm.html [Consultado: junio 2003]. 


\section{Investigacón Biblicteedógica v. 18 No. 36 enero/ junio de 2004}

[...] la obtención de beneficios sociales tangibles e intangibles (educativos, científicos, así como la obtención de posibles beneficios económicos directos y netos, son dos metas irrenunciables en estos tiempos de la gestión del patrimonio. ${ }^{7}$

También relacionado con el patrimonio cultural existe otro asunto que genera diversas controversias, especialmente en nuestro país: la reproducción del objeto cultural frente a los derechos de los autores. La realidad mexicana de esta cuestión, finalmente patrimonial, puede compararse con las iniciativas y soluciones adoptadas en otras latitudes para resolver problemas relacionados con el reconocimiento y la prioridad del interés público.

El interés público es difícil de definir cabalmente, pero es la idea que orienta (o debería orientar) y define la mayor parte de las acciones del Estado. Casi todas nuestras leyes en materia de cultura expresan abiertamente que el objeto o la finalidad sobre las que actúan tiene un interés público. En términos generales, este interés se puede comprenderen relación directa con el beneficio social que producen las políticas de Estado.

Es en dirección de las políticas de Estado hacia donde deberíamos orientar nuestras reflexiones y posiciones respecto al derecho de autor en el marco de los bienes que integran el patrimonio cultural mexicano. La finalidad de toda preservación de la herencia cultural, representada en ese patrimonio, es precisamente el interés público y, por tanto, el beneficio social de su aprovechamiento. Empero ésta es la última finalidad que parece prevalecer en nuestras leyes y en las políticas que deben regular, de ahí que el lugar de las instituciones de cultura permanezca relegado en la realidad social pero no en el discurso que las fundamenta.

Sin embargo, en este sentido lo contradictorio de la preservación institucional es que esta tarea significa retirar el acceso a los bienes patrimoniales para protegerlos de aquellos para quienes supuestamente se preserva. Partimos entonces de reconocer que las colecciones conservadas en archivos, bibliotecas y museos de titularidad pública, representan un patrimonio histórico que es propiedad de todos los ciudadanos. Empero este reconocimiento, "[...] se ha interpretado en ocasiones como un campo para la disputa y no como un terreno para la confluencia de responsabilidades". 8 Por otro lado, no habría que olvidar que esas colecciones constituyen un recurso valioso para la sociedad, independientemente de qué tipo deinstitución (pública oprivada) las custodie.

Es en este sentido en el que debemos analizar las leyes de derechos de autor y de transparencia a la información pública. La primera LeyFedaral dd DeechodeAutordeclara, en su artículo primero, que tiene por objeto la salvaguarda y promoción del acervo cultural de la nación, ${ }^{9}$ así como la defensa de los derechos de los autores. Sin

7 Josep Ballart Hernández y Jordi Juan i Tresserras. Getióndd patrimmioaltural. Barcelona: Ariel, 2001. p. 123.

$8 \quad$ Ibidem p. 173.

9 Ley publicada en el DianioOfidal delaFederacónde 24 de diciembre de 1996. Texto disponible en http://www.cddhcu.gob.mx/leyinfo/pdf/122.pdf

[Consultado: noviembre de 2003] ültima reforma del 23 de julio del 2003. 
embargo en el artículo 148 de la ley, referido a la utilización de obras artísticas ya divulgadas o publicadas, se incluyen ciertas excepciones. Una de éstas permite la copia, por una sola vez, en bibliotecas y archivos, siempre que sea "por razones de seguridad y preservación", y solamente cuando la obra esté agotada y en peligro de desaparecer. También permite la reproducción de obras conocidas siempre que sea con fines deinvestigación, asícomo para el uso privado personaly sin fines delucro.

La ley vigente también autoriza la reproducción, comunicación y distribución por medio de dibujos, fotografías y procedimientos audiovisuales, de las obras que están visibles en lugares públicos. Por ejemplo, la obra de los muralistas mexicanos que engalana varios edificios públicos. Éste sería el tipo de reproducción que beneficia mayoritariamente a las instituciones culturales de custodia de nuestro patrimonio documental. No obstante, sus colecciones no son precisamente visibles desde lugares públicos, pese a que podríamos entender como lugar público el interior de las instituciones, aunque dudo que ésta haya sido la intención de los legisladores. Si quisiéramos, podríamos interpretar que esta descripción se refiere a las obras en exhibición en museos, bibliotecas y archivos. Pero las leyes no deberían interpretarse sino comprendercorrectamente el objeto que legislan.

El poder legislativo del país ha olvidado que uno de los principales problemas de las bibliotecas es, por un lado, la conservación y preservación de las colecciones custodiadas, $y$, por el otro, el aprovechamiento de y el acceso a esas mismas colecciones que custodia. ${ }^{10}$ Recordemos que el derecho de autor se entiende compuesto por dos partes: el derecho moral inalienable, imprescriptible, irrenunciable e inembargable; y por otro lado el derecho patrimonial que se refiere al aprovechamiento de la obra en cuestión; es decir, a la obtención de recursos económicos derivados de su reproducción y comercialización como productos culturales. El primero de estos derechos no puede cederse a nadie en ningún caso, mientras que el segundo sí. Dicha cesión de derechos puedehacerse entre personas o a favor de unainstitución.

Este es el punto importante en relación con las colecciones del patrimonio cultural mexicano. La ley debió haber reconocido su derecho patrimonial sobre los objetos de custodia para favorecer así el financiamiento de sus actividades y de ese modo beneficiar también a lo social. Pero este reconocimiento patrimonial no puede hacerlo para bibliotecas, archivos y museos de titularidad pública, porque ya existen instituciones a las que les ha sido otorgado ese derecho: el Instituto Nacional de Antropología eHistoria (INAH) y el Instituto Nacionalde Bellas Artes (INBA). ${ }^{11}$

Reconocer y otorgarle este derecho a las instituciones culturales requeriría reformar las leyes involucradas, es decir, la LeyFęaral deMonumentosyZanasArquedógicos HistóicosyArtísticos y las leyes del INAH y del INBA, así como la LeyGeneral deBiblidteasy, si

10 Cfr, Jonathan Furner. “Digital images in libraries: an overview”, en VINE. No. 107 (1997) p. 3.

11 Artículo $38^{\circ}$ y 39 del Reglamento de la Ley Federal de Monumentos y Zonas Arqueológicos, Históricos y Artísticos, publicado en el DianioOficial delaFedkacoóndel 8 de diciembre de 1975 y reformado en 1993. 


\section{Investigacón Biblicteedógicav. 18 No. 36 enero/ junio de 2004}

existieran, las leyes relativas a los archivos y museos. ${ }^{12}$ Todo ello implicaría construir un entramado legal capaz de integrar la cuestión patrimonial de la cultura desde una sola posición del estado: el beneficio social de la cultura como un derecho fundamentaldelos ciudadanos.

Lo que resulta interesante en esta discusión mexicana (que ha creado y propiciado más de una polémica) sobre la relación directa entre derechos culturales y el derecho de los autores, es que no puede reflejarse en los espacios de discusión internacionales. En efecto, la mayor parte de los tratados escritos relativos al patrimonio cultural, desde la salvaguarda hasta las políticas culturales, no han integrado en su reflexión el lugar que tiene el derecho de autor frente al derecho cultural, ni el que tiene el derecho a la información de la sociedad, en esta materia tan particular. Esto es así porque en materia de patrimonio cultural el primer referente de actuación siempre será el interés público, porque es éste el que justifica toda protección y conservación de los bienes patrimoniales, pese a las contradicciones que hemos mencionado.

Por tanto la ley, en esta materia, debería privilegiar el interés público y favorecer la integración a él de los intereses diversos. Desde mi particular punto de vista no veo mayor complicación en reconocer los derechos patrimoniales de las obras custodiadas en bibliotecas, archivos y museos para estas mismas instituciones. Pero esta afirmación sería contraproducente para un instituto como el INAH, omnipotente y omnipresente en materia de patrimonio cultural. Personalmente sigo creyendo que las leyes mexicanas en materia de cultura son ingenuas al considerar que un problema de tal envergadura puede resolverse con posiciones únicas y no plurales, como corresponde a la naturaleza del patrimonio cultural.

La experiencia de otros países en relación con estos temas nos muestra interesantes ejemplos sobre proyectos normativos que buscan conciliar los intereses y las expectativas que se mueven alrededor del patrimonio cultural. Por ejemplo, el sitio en la red del patrimonio canadiense tiene un espacio dedicado a la creación y gestión de contenidos digitales. ${ }^{13}$ Ese espacio presenta propuestas muy interesantes que serían una guía para la reflexión. Estas discusiones en otros países, no exentan, en ningún momento, la consideración sobre los derechos de autor, pero estos mismos derechos cobran necesariamente un matiz diferente cuando se toma en cuenta el trabajo de las instituciones culturales y públicas como bibliotecas, archivos y museos. ${ }^{14}$

Sabemos que la salvaguarda del patrimonio cultural de todos y cada uno de los objetos que lo integran requiere de ingentes recursos materiales, humanos y financieros. El derecho patrimonial sobre sus colecciones permitiría establecer los recursos

12 Por increíble que parezca, a nuestros legisladores no sólo les ha faltado acuerdo político en esta materia, sino específicamente interés pese a la importancia de esta leyes. No hay que olvidar que el Archivo General de la Nación funciona por reglamento sin una ley que lo avale.

13 Información disponible en http://www.chin.gc.ca/Francais/Contenu_Numerique/index.html [Consultado: junio 2003]

14 Texto disponible en http://www.chin.gc.ca/Francais/Pdf/Propriete_Intellectuelle/Guide_ Droit/guide_droit.pdf [Consultado: junio 2003] 
necesarios, tanto para las tareas de salvaguarda como para las de difusión y conocimiento, que son sumamente relevantes para garantizar no sólo la conservación sino, especialmente, la transmisión de los valores que representan estos bienes patrimoniales.

En nuestro país, debido a extraños procesos sociales, hemos terminado por pensar que la economía del patrimonio cultural es un aspecto nefasto y negativo para todos. ${ }^{15}$ Esta apreciación incluso afecta el préstamo de piezas originales de nuestras instituciones, sin considerar que realizar este tipo de actividad cultural (siempre bajo condiciones de seguridad), favorecería el disfrute y acceso a piezas originales de otros países. Esta materia tan especial, la del patrimonio cultural, está expuesta necesariamente a abusos de todo tipo, por eso necesitamos una ley actualizada, consciente de las problemáticas e interesada en favorecer la participación regulada de todos los intereses; es ésta una de nuestras asignaturas pendientes.

En la elaboración de esta ley, como en la de todas aquellas que son necesarias para construirle un espacio integral para al patrimonio, no debemos obviar el aspecto de la economía por más que podamos pensarlo como abominable. "La economía no es el único terreno común de entendimiento entre los individuos y los pueblos: no puede sustituir a los valores de la cultura. Hay que dar a la cultura lo que es de la cultura y a la economía lo que corresponde a la economía. Un economicismo desbocado de nuevo cuño sólo puede redundar en perjuicio del bien patrimonial y causar un mayor empobrecimiento aún que el tradicional expolio ciego e insensible. El patrimonio [cultural] no es ni puede ser una mercancía como cualquier otra, como ya hemos visto". ${ }^{16}$

Desde esta perspectiva debemos comprender que la preocupación legal y la instrumentación de políticas culturales basadas en un marco normativo, no debe olvidar que el patrimonio cultural de una sociedad no sólo se conforma con la herencia del pasado sino también con todo aquello que aportamos en el presente. La plena comprensión de esta dualidad del patrimonio, que comprende el pasado y el futuro, debería determinar nuestras reflexiones. Pero seguramente las generaciones venideras construirán y fundamentarán sus propios valores sobre el patrimonio. Garantizar la salvaguarda de éste y asegurar los derechos culturales y de información les aportará la mejor herencia que podemos darles: la posibilidad de elegiry de decidir sobre su pasado.

\section{ORIGIN ALIDAD Y DERECH OS DE AUTOR: LA FUNCIÓN SOCIAL DEL PATRIMONIO}

Todo universo cultural de bienes patrimoniales se encuentra permanentemente expuesto al deterioro y la destrucción. Son innumerables los factores que permiten estas pérdidas patrimoniales que nos afectan directamente a todos, ya que el menoscabo de

15 Cfr. Amalia Cardos de Méndez, Marcia Casto-Leal Espino y Roberto Cervantes Delgado. "La política de uso y abuso del patrimonio cultural", en Patrimaniohistónicoyaltural deMéxica IV Semana Cultural dela Direción deEtndoǵa yAntropolóáa Social. México: INAH, 2001.

16 Joseph Ballart Hernández y Jordi i Tresserras. Op Cit p. 124. 


\section{Investigacón Biblicteedógica v. 18 No. 36 enero/ junio de 2004}

un objeto cultural en cualquier latitud significa siempre una pérdida para toda la humanidad. Los lamentables ejemplos recientes de Kosovo e Irak, son sólo una muestra terrible del riesgo exponencial que no puede ser detenido ni siquiera con las buenas intenciones de la UNESCO (a través de sus recomendaciones y convenciones), de las Organizaciones No Gubernamentales, ni delas manifestaciones sociales.

Este riesgo permanente nos lleva a buscar diversos mecanismos para reproducir los objetos culturales, acercárselos a la sociedad y transmitir así la importancia de su salvaguarda. La reproducción de originales no es un aspecto nuevo en la historia sino que ha sido necesaria para la educación artística e incluso para la formación en nuestros valores culturales. La realidad es que no todos los seres humanos podemos gozar del privilegio de estar frente a una obra maestra de la antigüedad como el Tikal, la Gioconda o Stonehenge. Pero mediante mecanismos de reproducción podemos acercarle esos objetos, y los valores que representan, a un público más amplio y con ello cumplir con el beneficio social que permite la salvaguarda patrimonial. "En general todas aquellas manifestaciones que pretenden 'desacralizar' el arte, acercarse al público, provocarlo e integrarlo buscan, entre otras cosas, cumplir con una función colectiva". ${ }^{17}$

En un universo ideal, los estados financiarían un viaje cultural anual para cuando menos uno de sus ciudadanos. Esto no ocurre ni siquiera en nuestros sueños, pero las instituciones culturales sí pueden acercarnos a la riqueza cultural de los pueblos mostrándonos aquello que los distingue y acercándonos al mismo tiempo como seres humanos. La herencia cultural nos muestra que las preocupaciones humanas más comunes han estado siempre presentes a lo largo de los tiempos: el amor, la guerra, la muerte, el futuro, la divinidad, etcétera. Gracias a la labor desempeñada por las instituciones culturales en otros países, éstas han sido consideradas en sí mismas como parte del patrimonio cultural.

Parece verdad de Perogrullo declarar que esas mismas instituciones representan valores culturales y sociales fundamentales obtenidos gracias al sacrificio de numerosas generaciones. Sin embargo en nuestro país esta verdad parece la menos cierta, y por ello son precisamente las instituciones culturales las menos protegidas, las más olvidadas y las menos favorecidas. Si esto no fuera cierto ¿cómo explicar que nuestras instituciones no tengan un reconocimiento legal, no participen en las políticas culturales y no tengan un financiamiento apropiado al valor social que representan?

Nuestras instituciones culturales enfrentan ciertas complicaciones en su acción cotidiana de salvaguardary difundir la cultura, una de éstas es la que las confronta con el derecho de autor en su acepción patrimonial. Pero la custodia de objetos culturales implica también garantizarsu contemplación.

Si los escondemos, si los guardamos en secreto, sea cual sea la razón que aduzcamos para ello, viene a ser como si no existieran. Y aunque sea la propia conservación quien impida o desaconseje la contemplación, estaríamos

17 Montserrat Galí. El arteenla ea delosmeelosdecommicaaón Madrid: FUNDESCO, 1988. p. 70 
cayendo en la paradoja de conservar algo que no existe o, lo que viene a ser lo mismo, algo que no cumple con su función. ${ }^{18}$

Ciertamente, la reproducción de un bien cultural sin contexto y sin explicación, no coadyuva a transmitir la comprensión de su valor, ni la de la "esencia" que lo ha hecho posible, como escribió Walter Benjamin. Pero reproducirla en un programa de interpretación o en una clase universitaria favorece la formación de conciencia social en torno a la salvaguarda de los bienes que integran el patrimonio cultural de una sociedad. Esta función social del bien patrimonial le es consustancial y por ello nunca deja de existir en el lugar de la posibilidad: es la que le ayudará a un ser humano a desarrollarse plenamente.

Sabemos que los mecanismos de reproducción de bienes culturales han sido varios y diversos, desde la copia fiel entre artistas hasta los procedimientos mecánicos más modernos. Estas reproducciones se han caracterizado, como todo, tanto por un uso racional y social, como por una explotación primordialmente económica. El poseedor privado de un bien cultural puede reproducirlo para generar recursos económicos y esto no es visto mal por ninguna normativa. Pero, cuando el bien es de dominio público, el asunto de la reproducción ya no parece tan agradable, aun cuando persiga el mismo fin económico. Lo que no parecemos distinguir claramente es la diferencia que existe entre explotación de un recurso cultural y el aprovechamiento de él.

Aprovecharlo significa usar racionalmente un recurso asegurandolas características que le otorgan valor. En este sentido, cuando las instituciones culturales reproducen están aprovechando los recursos de los que disponen, dado que el monto financiero obtenido por la reproducción es usado en beneficio de aquellos bienes que custodia. En efecto, los recursos obtenidos por este procedimiento pueden servir para mejorar o implementar las medidas medioambientales necesarias para conservar objetos culturales, o para emprender programas de difusión, como pueden ser las publicaciones o las exhibiciones, pero también para disponer de un ingreso que les permita adquirir una pieza invaluable. Si se observa bien, todas estas acciones tienen un profundo beneficio social, aun cuando nos parezca que el fin no justifica los medios.

La experiencia de otros países en esta materia no tiene que ser vista siempre como la necesidad imperiosa de copiar un modelo ya probado, sino como la posibilidad de implementar en nuestro país mecanismos que favorezcan la conservación y la difusión de bienes culturales. Existe un ejemplo que funciona perfectamente en esta argumentación: el de la reproducción de bienes culturales en bibliotecas y archivos, tanto públicos como privados. La mayor parte de los objetos que son custodiados por estas instituciones de cultura no posibilitan el acceso directo por parte de la sociedad, porvarias razones.

18 Juan Ignacio Macua de Aguirre. "Patrimonio ¿Para qué?: disfrute, uso y abuso de los bienes culturales", en El patrimmioHistóncoArtísticoEspañd / coordinador Luis A. Ribot García. Madrid: Sociedad Estatal España Nuevo Milenio, 2002. p. 196. 


\section{Investigacón Biblicteedógica v. 18 No. 36 enero/ junio de 2004}

Entre tales razones se encuentran dos principales: la primera es que el objeto no permite su manipulación directa si ésta no es realizada por una persona que tenga conocimiento del objeto; y la otra es que los códigos culturales que hicieron posible ese objeto documental no son del conocimiento público sino más bien el dominio de ciertos especialistas; en efecto, no es siempre fácil comprender el contenido del objeto documental. ¿Qué sentido, por ejemplo, tiene abrir a la consulta pública un códice prehispánico, arriesgando su conservación, cuando son pocos quienes comprenden realmente su sentido?

Por el contrario, si ese mismo códice prehispánico es reproducido y presentado con una explicación que transmita (y especifique y amplíe) su importancia y su sentido a un público más extenso, estaremos favoreciendo el conocimiento público sin exponerlo al deterioro material, y de ese modo permitiremos un mejor acceso y disfrute a un bien cultural. En una exhibición institucional donde se difunda un original, la sociedad sólo podrá acceder y disfrutar de una sola parte del material y cuando mucho de una cédula informativa del mismo. En cambio una reproducción completa del objeto, con información especializada y contexto, le permite a un mayor número de personas admirar hasta los mínimos detalles de ese mismo objeto.

No hay que olvidar nunca que las medidas de conservación, protección y valoración, son siempre referidas a un original, y que sólo la reproducción permite acceder y disfrutar de un bien patrimonial sin menoscabo del original. Empero, en más de una ocasión la reproducción ha sustituido al original en el lamentable caso de pérdida irremediable. Recordemos el desconsolador caso del incendio de nuestra Cineteca Nacional para comprender la importancia de la reproducción en el marco de una visión patrimonial. Para lamentarnos más, en el caso de numerosos documentos históricos mexicanos sólo nos queda la reproducción y en el mejor de los casos no se trata de copias fieles sino de transcripciones efectuadas por expertos. Dicha situación se ha propiciado porque no hemos sido capaces de proteger cabalmente a nuestras instituciones de culturay, por ende, a los objetos que custodian.

A este respecto nadie puede negar que el original contiene el valor supremo, de ahí que debamos asegurar por todos los medios posibles su adecuada salvaguarda. Pero el problema de salvaguardar los bienes patrimoniales aumenta necesariamente con el paso del tiempo, y natural y simplemente no podemos proteger todos los bienes conservados. De ahí que entre el grupo general de los objetos culturales, debamos seleccionar unos cuantos para elevarlos al máximo reconocimiento de protección y valoración: el de ser bienes culturales. Esta selección se basa en criterios de originalidad, unicidad, singularidad y representatividad. Son los verdaderos testimonios del pasado; conforman nuestro legado, y a través de ellos dejamos que las generaciones establezcan un diálogo permanente con el tiempo.

La reproducción de un bien cultural custodiado por una biblioteca o un archivo no sólo favorece el conocimiento a través de la investigación especializada, sino que permite que ésta pueda aportar su interpretación para valorar ese objeto, y le transmite a la sociedad tanto el continente (lo material) como el contenido (el significado) de 
ese bien cultural. Pero la primera tarea de la salvaguarda implica el conocimiento de los objetos que se custodian, por eso no sólo se privilegia la investigación sino que se la reconoce de interés público.

Las reproducciones, como parte de la tarea que implica a las instituciones de cultura, no sólo deben regularse para evitar malos usos, sino que por esta condición normativa no deben prohibirse sino favorecerse, sobre todo cuando la finalidad que las inspira sea el beneficio social. Un beneficio que no es solamente reconocido desde la perspectiva cultural sino también desde la económica, siempre y cuando el monto financiero recuperado se reutilice en labor cultural. Ahora bien, en el mundo digital que nos ofrece la tecnología de la información las posibilidades de reproducción alcanzan cotas nunca antes imaginadas. En este entorno la idea de original cobra otro tipo de matices sobrelos que debemos reflexionar.

En primer lugar, el original digital ya no es el original en sí mismo sino una reproducción de éste. Desde esta perspectiva en el mundo digital cohabitan dos tipos de objetos: los que reproducen un original material, y los que son diseñados y creados para ser digitales desde el principio. En este último caso, por ejemplo, la impresión del objeto ya es una reproducción. En el primer caso, el del original material reproducido en digital, su impresión es ya una reproducción de la reproducción.

En el caso del objeto creado originalmente en el mundo digital, debemos considerar al producto como contemporáneo y por tanto sujeto a las leyes vigentes de derechos de autor. El caso de la reproducción digital de un objeto material no puede ser analizado desde la misma perspectiva, puesto que el "original" ya existía antes. Ahora bien, ciertamente el trabajo de la reproducción lo ha hecho alguien, pero mantengamos esto en su justa medida. Si consideramos el ejemplo de las bibliotecas y archivos, y la necesaria reproducción que ya hemos expuesto, tendríamos que tomar en cuenta otra cosaimportante.

Si la reproducción se enmarca en un proyecto institucional de digitalización, el proceso incluye la selección, la preparación del material que se va a digitalizar y, por supuesto, los mecanismos de acceso como la descripción y el análisis del objeto reproducido. ${ }^{19}$ En estos casos particulares el derecho de autor en sus dos vertientes, moral y patrimonial, son de la institución que ampara la realización del proyecto. Estos proyectos de digitalización en bibliotecas y archivos pueden ser para difundir las colecciones, pero también paragarantizar la conservación mediante un cambio de soporte.

En ambos tipos de proyecto suelen crearse varias imágenes. Una necesariamente de alta calidad, que permita la reproducción según los intereses y garantice la conservación, y las otras que se derivan de aquélla. Este proceso, aun cuando se realiza bajo las más estrictas normas de seguridad, debe garantizar que no se requerirá volvera exponer al objeto original para los mismos fines. ¿Cuál es el original en este mundo digital? Podríamos considerar que el primero de alta calidad, pero al reproducirse o

19 Hubert Fondin. Letraitement numériquedes dbaments París: Hermes, 1998.p. 147 


\section{Investigacón Biblicteedógica v. 18 No. 36 enero/ junio de 2004}

copiarse para garantizar la estabilidad tanto del producto como del proceso, estaríamos hablando entonces de varios originales.

La cuestión sobre la originalidad puede complicarse aún más si la imagen digital se obtiene de un microfilm elaborado con años de anterioridad. Pero, la ventaja de esta reproducción digital es básicamente su posibilidad de reproducción ${ }^{20}$ constante e infinita (mientras sea estable) en donde el problema de la originalidad digital resultaría lo menos importante. Como puede observarse, la originalidad en el mundo digital es relevante siempre y cuando no redunde en detrimento del material original, el objeto de la valoración y la representación cultural. Lo más importante en este mundo digital es que la finalidad de beneficio público dela reproducción no se vea afectada sino al contrario.

Estas preocupaciones en otros países, como se puede advertir en la producción de discos compactos y de páginas de Internet, privilegian el producto final, aunque no se hayan resuelto de forma definitiva los derechos de autor en su vertiente patrimonial. Nadie discute la autoría de un Goya o un Manet y tampoco que una reproducción de cualquiera de las obras de estos genios de la pintura, obtenida en una institución cultural, puede generar un importante recurso económico que al final beneficia siempre elinterés público.

Sin embargo en México podemos observar la escasa presencia de proyectos institucionales en la red que permitan acceder y disfrutar al público en general, local y nacional, de cuando menos una parte representativa de la riqueza contenida en nuestro patrimonio cultural. Y la misma situación existe en la producción de discos compactos que le permita a las instituciones diversificar su financiamiento. Es muy probable que estos sucesos puedan explicarse por el entramado jurídico que hemos creado (limitantey limitado) que no nos permite explorar todas sus posibilidades.

\section{NUEVOS CAMIN OS PARA LA IN VEST IGACIÓN PAT RIMONIAL: LA FOTO- GRAFÍA DIGIT AL Y SUSIMPLICACIONES}

Frente a nuestro panorama nacional, los proyectos a nivel mundial enfocados a la digitalización de fuentes históricas relevantes crecen exponencialmente y le ofrecen a la investigación especializada nuevas fuentes de información que representan la riqueza cultural custodiada en bibliotecas, archivos y museos. Estos productos, discos compactos y páginas en la red, en más de una ocasión han sido generados por preocupaciones de investigación. ${ }^{21} \mathrm{Y}$ de este espacio privilegiado, todos ellos evolucionan hacia proyectos institucionales de gran envergadura que permiten asegurar la continuidad delosinteresesiniciales.

20 Arnaud Ramière de Fortanier. "L'accès sur Internet: une politique d'ouverture pour les arcives", en Lanuméisationauservicedelapréservationedelavalonisationdesardives París: Direction des Archives de France, 1998. p. 105.

21 Sean Townsend, Crecida Chappell y Oscar Struijvé. DigitisingHistary: A GuidetoCreatingDigtal Re sarcesfromHistarical Douments Great Britain: The David Brown Book Company, 1999. p. 4. 
En esta situación se encuentra el proyecto Iluminadinesdel Ministerio de Cultura de Francia, ${ }^{22}$ que actualmente permite la consulta digital de diversos elementos de manuscritos iluminados medievales custodiados por las bibliotecas públicas francesas. Desde la página en la red se ofrece la posibilidad de acceder gratuitamente a 14,000 imágenes, a través de un instrumento de búsqueda sencillo. Seamos conscientes de que esta riqueza representada en imágenes digitales, es considerada una de las más importantes joyas del patrimonio cultural francés.

Si bien no es el único proyecto de esta importancia, sí representa un esfuerzo más que loable por ofrecerles, tanto al investigador especializado como al público en general, una ventana de posibilidades para conocer y difundir unos bienes culturales que normalmente son de acceso sumamente restringido. Claro que para conocer estas piezas originales se hace necesario un viaje a Francia, sin embargo con este instrumento ciertos traslados pueden llegara serinnecesarios.

La oferta del Ministerio de Cultura francés de imágenes digitales sobre diversas piezas del patrimonio es una de las más importantes a nivel internacional. Todo esto muestra un verdadero interés por la difusión de ese patrimonio y de los valores que representa. Empero, el esfuerzo no es aislado ni solamente estatal, por el contrario, implica a varias instituciones de investigación y educación superior que participan activamente en la elaboración de esos productos y que van desde los contenidos y el diseño hasta la creación y adaptación de herramientas tecnológicas que permiten esta finalidad.

Para un investigador estos instrumentos pueden representar un fondo permanente de materiales, tanto en su trabajo cotidiano como cuando realiza las tareas de docencia o divulgación. Contrastemos esta realidad con la nuestra, que ni siquiera puede ofrecerle a los ciudadanos mexicanos un instrumento digital que nos permita conocer y disfrutar de las joyas de nuestro patrimonio documental: los códices mexicanos. Parte de estos códices, entre otros objetos documentales, fue ya reconocida como Memoria del Mundo en 1997, pero sólo hasta el año 2001 los internautas pudierongozarde una parte de este valor cultural. ${ }^{23}$

Las páginas institucionales, como la del INAH, no ofrecen todavía un acervo de tal magnitud para que los ciudadanos podamos acceder y disfrutar a nuestra riqueza patrimonial. Aunque habría que precisar que el Archivo General de la Nación ofrece cuando menos un documento relevante de su colección al mes en reproducción digital, que está disponible a través de su página en la red. Pero esta oferta cultural, que debería ser una práctica común a pesar de las diferencias institucionales en materia de recursos, todavía no es una realidad en México.

22 Información disponible en http://www.enluminures.culture.fr/ [Consultado: junio 2003].

23 El programa internacional coloca en la red una "sala de lectura" para que los visitantes vean los objetos reconocidos y puedan apreciar la riqueza cultural que los llevó a tal reconocimiento. En la mayor parte de los casos sólo se trata de cinco imágenes de buena calidad y poco tamaño. 


\section{Investigacón Biblicteedógica v. 18 No. 36 enero/ junio de 2004}

Por otra parte en el campo de lo privado podemos encontrar otro tipo de iniciativas como la compañía Octavo, ${ }^{24}$ que ofrece productos digitales de impresos antiguos (obras completas) a color y en formato PDF. Los productos de esta iniciativa son posibles gracias a la participación de bibliotecas americanas que funcionan como socios institucionales (i.e. The Bancroft Library o The Library of Congress), pero también tienen socios estratégicos, como el Research Libraries Group. 25

Este ejemplo, en particular, nos muestra cómo los productos elaborados por iniciativas privadas benefician en gran parte a instituciones culturales del dominio público, ya que el producto final les permite difundir y conservar los originales que en muchos casos las distinguen y honran. Pero la iniciativa también beneficia a investigadores y el público general interesado en esta oferta de productos culturales.

Por extraño que nos parezca estos productos no son de un alto costo. Al contrario, son medianamente accesibles. Una institución educativa puede adquirirlos y con ello crear un espacio más amplio para el acceso y disfrute de bienes culturales. Efectivamente, las posibilidades del mundo digital no sólo se han utilizado para proteger y difundir bienes de naturaleza documental, existen actualmente paseos virtuales por elementos del patrimonio mundial, como las pirámides de Egipto, las Cuevas de Altamira ola ciudad de Venecia, entre otros.

Sin embargo para la investigación que requiere fuentes documentales, este tipo de herramienta ofrece numerosas alternativas para todas las actividades implicadas en su labor cotidiana. Prácticamente todo investigador que trabaja directamente con elementos del patrimonio cultural, ha conformado a lo largo de sus tareas un importante acervo de recursos gráficos a partir de los cuales ha apoyado su propia investigación, así como la docenciay la divulgación.

Este es nuestro caso. La investigación que realizamos en el Centro Universitario de Investigaciones Bibliotecológicas de la UNAM sobre el patrimonio documental mexicano, ha conformado durante cuatro años un acervo de fotografías digitales de casi 8,000 piezas. Estas fotografías muestran la riqueza de varias bibliotecas y archivos, lo que nos ha permitido analizar con mayor detalle y profundidad el objeto de nuestras preocupaciones. La fotografía digital es básica y está compuesta por imágenes en formato JPG de resolución mediana y en un tamaño aproximado de $1.4 \mathrm{Mb}$.

El equipo que nos ha permitido conformar este acervo de imágenes se lo debemos al financiamiento de dos proyectos, uno de la propia universidad (PAPIIT) y otro del CONACYT. Este equipo se compone de cámaras digitales, analógicas, escáner, computadoras portátiles, unidades de almacenamiento ZIP y unidades de grabación e impresión de discos compactos. Dada la naturaleza del financiamiento de la investigación hemos denominado a la reproducción "digitalización de bajo costo". Además, el equipo nos ha permitido dotar a las instituciones de imágenes digitales que pueden serutilizadas en diversos productos propios.

24 Información disponible en http://www.octavo.com/index.html [Consultado: junio 2003].

25 Información disponible en http://www.rlg.org/toc.html [Consultado: junio 2003]. 
Gracias a estas imágenes y pasando por encima de las complicaciones que hemos vivido para obtenerlas, podemos hacer las reflexiones que en este texto hemos presentado. En efecto, las imágenes son solamente una parte de la investigación y han enriquecido notablemente nuestras perspectivas iniciales. Al mismo tiempo este acervo gráfico de fotografía digital nos ha permitido mostrarle al público en general, la riqueza cultural que defendemos, pero también la cruda realidad institucional que caracteriza a los archivos y bibliotecas de México.

Si bien no podemos comparar este esfuerzo con lo que representaría un proyecto de digitalización institucional de mayor alcance, sí podemos reconocer claramente que el desarrollo de nuestra investigación ha hecho que las instituciones reflexionen sobre el problema que representa la reproducción de los objetos que custodian, así como las posibilidades que abriría su adecuado aprovechamiento para diversificar el financiamiento mediantela elaboración de productos concretos.

En lo que se refiere específicamente al derecho patrimonial implicado en estas fotografías, reconocemos que este derecho debe ser de la institución que autoriza la reproducción. En el caso del derecho de autor en su vertiente moral, el proyecto de investigación prevalece sobre las personas. Esto quiere decir que la autoría es un proyecto de investigación, y no la persona que realiza las fotografías. Así como requerimos la autorización por escrito de la institución para difundir estas imágenes, solicitamos que al utilizarlas reconozcan que han sido posibles gracias a un proyecto de investigación determinado. Esta decisión no es gratuita ni altruista. La investigación universitaria siempre le cede el derecho patrimonial a la institución que cobija el trabajo delinvestigador que la realiza.

En estas ideas puede apreciarse que la prioridad es el interés público y el beneficio social que se deriva de la difusión de las imágenes realizadas a lo largo del proyecto. En muchos casos, la difusión de estas imágenes no sólo han permitido acercar la problemática patrimonial a las personas que están interesadas en su estudio y análisis; también han permitido sensibilizar a quienes ejercen la custodia institucional sobre la misma riqueza que tutelan, y dan a conocer a un público más amplio lo que resguardan nuestras bibliotecas y archivos. Una parte importante de estas imágenes muestra, por primera vez a una sociedad que los desconoce totalmente, detalles poco conocidos que caracterizan a estos objetos documentales.

Sin embargo nuestra aspiración no se agota ahí. Deseamos que ese acervo gráfico alcance a más personas y que su difusión contribuya a que se conozca nuestra riqueza patrimonial y que la ciudadanía se sensibilice sobre la importancia de garantizar su adecuada salvaguarda. Esta finalidad parte de una premisa fundamental que ha evolucionado a lo largo de la investigación: no podemos proteger lo que no valoramos. Con este ánimo pretendemos generar discos compactos específicamente dedicados a difundir, en continente y contenido, los objetos que nos son más interesantes de nuestro patrimonio documental: los libros antiguos. También pretendemos difundir contenidos digitales a través de Internet para toda la sociedad, nacional einternacional. 


\section{Investigacón Biblictedóǵgia v. 18 No. 36 enero/ junio de 2004}

Empero y desgraciadamente nuestras aspiraciones se confrontan con intereses de otro orden legal, institucional y social para el que esperamos encontrar respuestas y consolidar argumentos capaces de convencer a otros acerca de la importancia de esta difusión, tanto para la institución de custodia de bienes culturales, como para la institución de educación superior que nos cobija y la sociedad en su conjunto. Frente a estas dificultades que hemos encontrado en el camino, nos alienta el trabajo de otros seres, cercanos y lejanos, que nos han mostrado la existencia de otras alternativas para losacervos fotográficos de carácter digital

\section{CONCLUSIONES}

En materia de imágenes digitales, en México tenemos que trabajar bajo lineamientos de cooperación e intercambio entre instituciones y personas para reformar el marco legal de la cultura: una reforma que reconozca que la difusión del patrimonio, como derecho cultural y de información de los ciudadanos, es una premisa insoslayable de la construcción de una sociedad verdaderamente democrática. Sin embargo el esfuerzo debe comenzar por hacer conscientes a los poderes públicos de que esta necesidad cultural no puede ser posible si no se invierte en la infraestructura necesaria que garantice el acceso y disfrute de las personas al patrimonio cultural mexicano.

Las iniciativas de otros países reflejan prístinamente la importancia de contar con planes y programas de desarrollo que establezcan claramente las finalidades y las agendas de trabajo. Por ejemplo, las iniciativas sobre la digitalización de bienes del patrimonio documental en Europa ${ }^{26}$ se inscriben en los programas generales para asegurar una sociedad de información sustentada en valores democráticos. Estas agendas de cumplimiento prácticamente cabal para todos los estados miembros de la Unión Europea, han dado lugar a una evaluación de los objetivos cubiertos y el análisis de las dificultades que presentaba su obtención. Con esta información es posible volver a diseñar un programa general de actuación, ${ }^{27}$ que reconozca los logros obtenidos pero también defina las dificultades.

En efecto, la coordinación no es de forma absoluta, sino que está abierta a todos los estados participantes. ${ }^{28}$ Un ejemplo como éste sólo nos muestra que con la carencia actual de políticas culturales de Estado simplemente no podremos garantizar la conservación de nuestra riqueza patrimonial para las generaciones venideras. Ni tampoco podremos asegurarle a la sociedad del presente un derecho de acceso y disfrute del patrimonio cultural mexicano. Desde nuestra perspectiva, debemos comenzar por

26 Texto disponible en http://europa.eu.int/information_society/eeurope/action_plan/pdf/actionplan_es.pdf [Consultado: junio 2003].

27 Texto disponible en http://europa.eu.int/information_society/eeurope/news_library/documents/eeurope2005/eeurope2005_es.pdf [Consultado: junio 2003].

28 Información disponible http://www.librari.beniculturali.it/coord_digit/nationalpages-1-it.html [Consultado: junio 2003]. 
conformarnos en grupos de trabajo con finalidades definidas y con agendas de trabajo que permitan diseñar posibles soluciones para los problemas que observamos (o padecemos) en la realidad socialactual.

Sin proteger adecuadamente las instituciones culturales en las que se custodian los bienes culturales de México, la ingente tarea que se nos presenta no podrá alcanzar su más profunda aspiración: el interés público y el beneficio social que conlleva la salvaguarda de nuestro patrimonio cultural. Si nosotros, somos los primeros en desconocer este lugar institucional, tengan la certeza de que los lugares de decisión mantendrán para la institución cultural la tónica que observamos actualmente: una existencia hueca en el discurso político y una realidad nada agradable en lo social.

\section{BiBLIOG RAFÍA}

BALLART HERNÁNDEZ, Josep y Jordi Juan i Tresserras. Gestióndd patrimonioaltural. Barcelona: Ariel, 2001.

COLLEMAN, Allison y Susan J. Davies. "Copyright and Collections: recognising the realities of cross-domain integration", en Jamal of TheSodeyofArdivists Vol. 23, no. 2 (October 2002) p. 223-232.

COMISIÓN EUROPEA. Digtisation ofLibraryMateials Repat of theConertationMeetingandWorkshop, hddinLuxembarg 14 deetrber 1998 / edited by Marc Fresko. Bruselas: EU. Directorate General, 1999.

CORSINI, Silvio. "Passe-Partout: banque internationale d'ornaments d'imprimerie", en BulleindesBiblidhèques deFrance T. 46, no. 5 (2001). p. $73-79$

DEVILLE, Jacques. "Les Bibliothèques dans le marché du patrimoine écrit et graphique", en Bullein des Biblidhèques deFrance T. 45, no. 2 (2000). p. 52-62

ÉLOI, Catherine. "Les images fixes numérissées à la Bibliothèque Nationale de France: constitution et traitement de la collection", en Bullein des Biblichèques deFrance T. 46, no. 5 (2001). p. 80-86.

FONDIN, Hubert. Le traitement numáique des dbaments París: Hermes, 1998.

FRESKO, Mark y Kenneth Tomb. Digtal PresevationGuiddines thestateof the art in libraies, msams and ardives Luxembourgo: European Communities, 1998. 


\section{Investigacón Biblicteedógica v. 18 N o. 36 enero/ junio de 2004}

FUNDACIÓN TELEFÓNICA. "El patrimonio histórico español y latinoamericano en recreaciones virtuales en Internet", en Restauracoón \& Rehabilitación: RevistaIntemacianal de PatrimanioHistónica No. 80 (octubre de 2003). p. 60-67

FURNER, Jonathan. "Digital images in libraries: an overview", en VINE. No. 107 (1997). p. 3- 7

GALÍ, Montserrat. Elarteenlaeradelosmeelosdecommicadón Madrid: FUNDESCO, 1988.

Handbook fordigital priets amanagementtod forpreservationandaccess / editor Maxine K. Sitts. Massachusetts: Northeast Document Conservation Center, 2000.

HUNTER, Gregory. Preservingdigital infomation New York: Neal-Shuman Publishers, 2000. (How-to-do-it Manual for Librarians; 93)

La imagen fotográfica en la altura digital / comp. Martín Lister. Barcelona; México: Piados, 1977.

KATTNIG, Cécile. Gestion \& difusión d'un fonds d'image París: NATHAN, 2002.

KITZENTHALER, Mary Lynn, Gerald J. Munoff y Margery S. Long. Ardives \& Manusmipts: Administration of Photographic Cdletions Chicago: The Society of American Archivist, 1984

\section{Libraries, msemsandardives Leegl IssuesandEthical ChallengsintheNewIn-} fomationEra/ edited by Tomas A. Lipinski. Maryland: The Scarecrow Press, 2002

LINE, Maurice B. "Les bibliothèques dans une économie de l'information: des bastions de la liberté d'information et de la culture", en Bullein des Biblicthèques deFrance T. 45, no. 2 (2000). p. 17-25

MACHUCA, Jesús Antonio. "Percepciones de la cultura en la modernidad", en Alteridades Vol. 8, no. 6 (1998). p. 27-41

Manual dedbamentadónfotogáfica / editor Félix del Valle Gastaminza. Madrid: Editorial Síntesis, 1999.

Lanuméisation auservicedela préervation đdelavalonisationdesardives París: Direction des Archives de France, 1998 
OSORIO ALARCÓN, Fernando. "Aplicación de imágenes digitales para la preservación y acceso de documentos gráficos con valor histórico", en LaboratorioMexicanodeImágenes. Revistadigtal, amalógicoydeconservación Texto disponible en http:/ / www.lmi.com.mx/revista/digital/12.html [Consultado: noviembre de 2003]

El patnimmioHistónicoArtísticoEspañd / coordinador Luis A. Ribot García. Madrid: Sociedad Estatal España Nuevo Milenio, 2002.

Patrimmiohistóncoyaltural deMéxica IV SemanaCultural delaDireccóndeEtndóa yAntropdoǵa Social. México: INAH, 2001

REILLY, James M. y Franziska S. Frey. RecommendationsfortheEvaluation of Digital ImagesProducedfromPhotographic, Microphotographic, andV ariousPaperFormat. Rochester: Image Permanence Institute: Rochester Institute of Technology, 1996

SÁNCHEZ VIGIL, Juan Miguel. "La fotografía como documento en el siglo XXI”, en DoumentacióndelasCieniasdelaInfommaión No. 24 (2001). p. $255-267$

TOWSEND, Sean, Crecida Chappell y Oscar Struijvé. DigitisingHistary: A GuidetoCreatingDigital ResarcesfromHistarical Doaments Great Britain: The David Brown Book Company, 1999.

LaUniversidadenlasocieladdd SigoXXI / Carlos Fuentes... [€. al.]. Madrid: Fundación Santander Central Hispano: FCE, 2001.

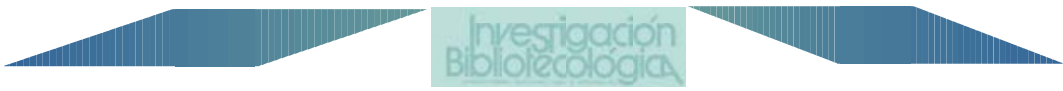

